\title{
45:
}

类

\section{A RESSIGNIFICAÇÃO DO MITO DE ORIGEM DA FAVELA PELA ARTE DE MAURÍCIO HORA}

- RAFAEL GONÇALVES DE ALMEIDA 1

1 Geógrafo. Doutor em Geografia pela Universidade Federal do Rio de Janeiro. Prêmio Capes de Melhor Tese de Geografia no ano de 2017. Professor do Instituto Federal de Educação Ciência e Tecnologia do Rio Grande do Norte (IFRN). E-mail para contato: rafaelalmeida08@gmail.com

Recebido em: 10/07/2019

Aprovado em: 22/10/2019

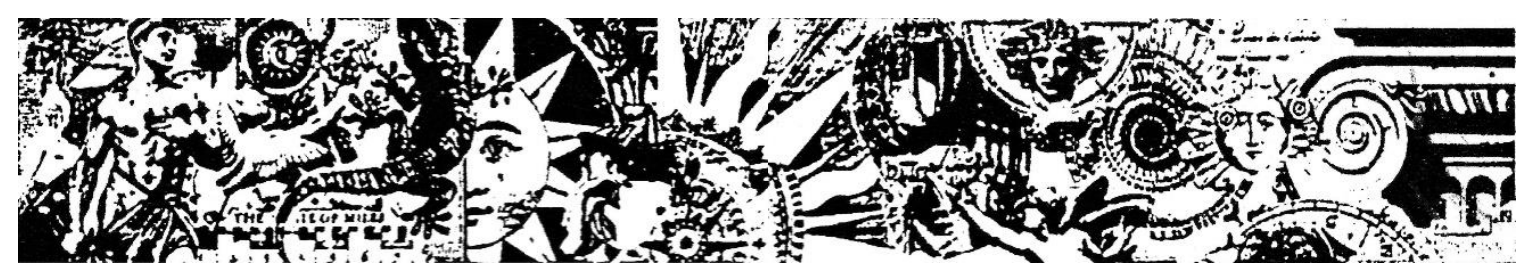

Resuma: D presente artigo fai adaptado de uma palestra realizada no dia 05 de julho de 2017, no Espaço Cultural BNDES, onde ocorreu a exposição de Maurício Hora, intitulada "Morro da Favela à Providência de Canudas". 0 artigo problematiza a assaciação entre a guerra de Canudas e a gênese das favelas do Rio de Janeira, discutinda o papel da obra de Euclides da Cunha e da "mita de origem da favela" na construçãa de um discurso exterior sobre a farmação histórica dessas comunidades e sobre as atributas de seus moradores: um discurso estigmatizante, racista e violento. Nesse sentida, buscamos refletir criticamente sobre a exposição de Maurício Hora, para argumentar que, a reivindicar a história de Canudos como parte de sua própria história, o artista reconstrói o passado e ressignifica o presente a partir de uma reinterpretaçãa desse mito de origem, crianda uma narrativa que é viva e plural. Palavras-Chave: favela; Rio de Janeira; fotografia; Maurício Hora. 


\section{6:}

THE RESSIGNIFICATION QF THE FAVELA MYTH OF QRIGIN BY THE ART OF MAURIÍII HDRA

ABSTRACT: THIS PAPER WAS ADAPTED FRDM A LECTURE HELD ON UULY 5TH, 20I7, AT THE BNDES CULTUIRAL SPACE, WHERE THE PHOTOGRAPHIC EXHIBITIIN OF MALRICIO HORA (ENTITLED "MDRRO DA FAVELA A PRQVIDENCIA DE CANUDOS") TOOK PLACE. THE PAPER QUESTIONS THE ASSOCIATIIN BETWEEN THE CANUDOS WAR AND THE gENESIS OF THE FAVELAS QF RI DE JANEIRD, DISCUSSING THE RDLE OF EULLIDES DA CUNHA'S WDRK AND THE "FAVELA MYTH OF QRIGIN" IN THE CONSTRUCTION UF AN

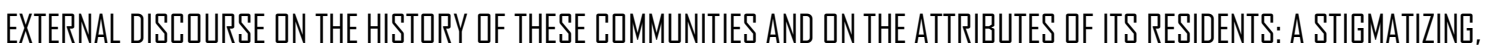
RACIST AND VIDLENT DISCDURSE. IN THIS SENSE, WE SEEK TO REFLECT CRITIICALLY ON THE EXHIBITIIN BY MALRICIO HORA, TO ARELE THAT, BY CLAIMING THE HISTORY DF CANUDOS AS PART OF HIS OWN HISTDRY, THE ARTIST RECDNSTRUCTS THE PAST AND RE-SIGNIFIES THE PRESENT, PRQDUCING A REINTERPRETATION QF THIS MYTH OF ORIGIN, AND CREATING A NEW NARRATIVE THAT IS VIVID AND PLURAL.

KEYWDRDS: SLLM; RID DE JANEIRD; PHOTOGRAPHY; MALRIICIO HORA

\section{LA RESSIGNIFICACIÓN DEL MITQ DE QRIGEN DE LA FAVELA POR EL ARTE DE MALRICIO HORA}

RESUMEN: EL PRESENTE ARTíCULD FUE ADAPTADO DE UNA CONFERENCIA REALIZADA EL DÍA 5 DE لULLIO DE ZOI7, EN EL ESPACIO CULTURAL BNDES, DONDE TUVD LUGAR LA EXPDSICIÍN DE MAURÍCIO HORA, IITULADA "MDRRO DA FAVELA A LA PRDVIDENCIA DE CANUDOS". EL ARTí́LUL PROBLEMATIZA LA ASOCIACIÓN ENTRE LA GLERRA DE CANUDUS Y LA GÉNESIS DE LAS FAVELAS DE RÍ⿴囗口 DE JANEIRD, DISCUTIENDD EL PAPEL DE LA DBRA DE EUCLIDES DA CUNHA Y DEL "MITO DE DRIGEN DE LA FAVELA" EN LA CONSTRULCIÍN DE UN DISCURSO EXTERIDR SOBRE EL DRIGEN DE ESAS COMUNIDADES Y SOBRE LUS ATRIBUTOS DE SUS HABITANTES: UN DISCLURSO ESTIGMATIZANTE, RACISTA Y VIOLENTD. EN ESE SENTIDO, BUSCAMUS REFLEXIDNAR CRÍTICAMENTE SOBRE LA EXPDSICIÓN DE MAURÍLII HORA, PARA ARGLMENTAR QUE, AL REIVINDICAR LA HISTORIA DE CANUDOS COMU PARTE DE SU PROPIA HISTORIA, EL ARTISTA RECDNSTRUYY EL PASADO Y RESIGNIFICA EL PRESENTE A PARTIR DE UNA REINTERPRETACIÍN DE ESE MITT DE QRIGEN, CREANDO UNA NARRATIVA QUE ES VIVA Y PLURAL.

PALABRAS CLAVE: FAVELA; RID DE JANEIRD; FUTOGRAFÍA; MAURÍLII HORA.

\section{O mito de origem da favela}

Desde que visitei a exposição de Maurício Hora, pela primeira vez, já sabendo que participaria desta roda de conversa, decidi que eu centraria a minha fala na experiência que tive ao percorrer a exibição. $\mathrm{E}$ decidi isto porque eu venho estudando a história das favelas já há algum tempo, e esta exposição mudou a forma como penso essa história. Então queria contar para vocês como foi que essa mudança aconteceu. Antes, porém, preciso falar um pouco sobre o pano de fundo da exposição, que toma como premissa que a gênese da favela se encontra vinculada ao conflito de Canudos.

Quando comecei a estudar a história das favelas do Rio de Janeiro, logo me deparei com o que Lícia Valladares chamou de "mito de origem da favela" (VALLADARES, 2000). Tal mito conta que a favela surgiu no final do século XIX num morro localizado no centro da cidade do Rio de Janeiro (o Morro da Providência). Soldados que retornavam do combate aos seguidores de Antônio Conselheiro, chegaram 
de Canudos e se instalaram no referido morro para pressionar o Ministério da Guerra a lhes pagar os soldos devidos (VALLADARES, 2000). O morro, contudo, se assemelhava a outro que se tornara muito conhecido durante o conflito de Canudos, por ter sido o último reduto dos combatentes que se insurgiram contra a República: o "Morro da Favella”. Além da lembrança dos soldados, o morro baiano foi, também, retratado pelo livro de Euclides da Cunha, "Os Sertões”, que rapidamente foi aclamado pela crítica, tornando-se uma das principais referências literárias da época.

Se a associação entre o morro baiano e o morro carioca surgiu da memória dos soldados combatentes, da presença da planta "favela" (ou "faveleira") no Morro da Providência, ou dos escritos jornalísticos e literários, não sabemos. O fato é que o morro carioca passou a ser conhecido como "Morro da Favella". Essa história da origem da "favela" foi contada e recontada durante décadas nas páginas dos jornais do Rio de Janeiro e reproduzida em estudos e documentos posteriores. Everardo Backheuser, em 1906, incluiu-a no relatório apresentado ao Ministro da Justiça e Negócios Interiores (BACKHEUSER, 1906); mais tarde, Alfred Agache inseriu-a no plano urbanístico da cidade, de 1930 (AGACHE, 1930); e Victor Tavares de Moura recontou-a numa palestra proferida no dia 3 de março de 1942 (MOURA, 1943). Desde então, o Morro da Providência (que ficou conhecido como Morro da Favella) entrou para a história como a primeira favela do Rio de Janeiro.

\section{Outra versão sobre a origem das favelas}

Essa história, que raramente é tratada como mito, sempre me causou algum desconforto. Afinal, por que um assentamento criado por um grupo de soldados ou sobreviventes de Canudos teria dado origem ou seria o ponto inicial da difusão de inúmeras outras comunidades similares nos morros do Rio de Janeiro? Não havia outros agrupamentos de casebres, constituídos por populações pobres, nos mesmos moldes da favela, no Rio de Janeiro, antes da última década do século XIX (quando ocorreu o massacre de Canudos)?

Na verdade, desde o século XVIII e especialmente durante todo o século XIX, as florestas das montanhas do Rio de Janeiro já abrigavam inúmeras aglomerações de mocambos, casas de taipa, casas de pau-a-pique, enfim, casebres de todo tipo (CAMPOS, 2004; KARASCH, 2000). Corcovado, Catumbi, Santa Teresa (então morro do Desterro), os morros de Laranjeiras, o morro do Castelo, as montanhas em torno da Lagoa e da 


\section{8:}

Gávea e, especialmente, os morros da Tijuca e do Andaraí; enfim, boa parte dos morros onde hoje encontramos favelas já estava ocupada por essas pequenas aglomerações de habitações populares.

Seus moradores sobreviviam do cultivo da mandioca, milho, feijão e outros alimentos básicos; do comércio do excedente que produziam; ou então do trabalho na cidade. Aliás, exatamente como os moradores das favelas faziam no início do século XX. Os habitantes desses assentamentos também eram majoritariamente negros, mas havia gente de todas as cores, de diversas origens étnico-raciais (CAMPOS, 2004). Esses agrupamentos de casebres eram perseguidos pelas forças de segurança do Estado e considerados assentamentos ilegais. No entanto, na época, não chamavam esses agrupamentos de "favela", seu nome era outro: era "quilombo".

$\mathrm{E}$ os quilombos, como todos sabem, eram comunidades formadas por muitos daqueles que fugiam e resistiam às correntes "civilizadas" dos senhores brancos. Todavia, os quilombos, ao menos na acepção da época, eram assentamentos cuja existência (e ilegalidade) dependia da escravidão. Depois de abolido o trabalho escravo, não há mais motivo de identificar "quilombos" para enviar tropas, reprimi-los e castigar os escravos fugidos. De fato, as poucas décadas que separam a identificação de "quilombos" e a generalização da palavra "favela" foi um período em que a existência de comunidades pobres residentes nos morros da cidade foi muito pouco mencionada.

Não obstante, considerando que as colinas do Rio de Janeiro já se encontravam habitadas muito antes de ter início a história das favelas, e que tais colinas não foram abandonadas por algumas décadas para depois serem repovoadas por uma população com as mesmas origens étnico-culturais e vivendo nos mesmos tipos de habitação; não nos parece incoerente supor que a emergência das favelas na cidade, como argumentou Campos (2004), tenha alguma continuidade histórica em relação aos quilombos do século XIX. É claro que no início do século XX, na esteira do aumento populacional e do processo de urbanização da cidade, muitos novos agrupamentos foram constituídos e, mesmo aqueles já presentes nas colinas do Rio, terminaram se adensando e adquirindo novas características.

De todo modo, a história que foi construída sobre a origem das favelas não fincou suas raízes nos quilombos. Por algum motivo, essa associação foi feita com o episódio de Canudos e o sertão nordestino. E a pergunta que nós temos que fazer é: o que significa vincular a guerra de Canudos à gênese das favelas da cidade? 


\section{Da "Favella" à Providência}

A associação entre o "reduto dos fanáticos" e o "reduto da miséria" - como diz Backheuser (1906), ao contar a história da toponímia do morro carioca - já estava estabelecida antes de Euclides da Cunha publicar seu livro sobre a guerra de Canudos, em 1902. Entretanto, seu livro exerceu forte influência sobre a sociedade da época, em parte, porque se coadunava com a ideia de que a origem dos problemas brasileiros se encontrava na existência de dois Brasis: um bárbaro, estagnado e primitivo, e outro mais suscetível de acolher a influência das correntes modernizantes (LIMA, 2013; SANTOS, 1978). A dualidade litoral/sertão, que o livro de Euclides ajudou a consolidar, permitia compreender a formação histórica dos obstáculos ao progresso do país, e construía uma imagem que serviria como parâmetro para as decisões dos agentes públicos que buscavam sua superação.

A associação entre o episódio de Canudos e o Morro da Providência permitiu transpor a dualidade litoral/sertão para a capital da República, constituindo uma nova dualidade: a cidade/favela (VALLADARES, 2000). Já na segunda década do século XX (ABREU, 1994), a palavra "favela" deixou de ser somente um signo toponímico para tornar-se um substantivo comum e uma classe de área.

Como afirma Valladares (2005), a obra de Euclides da Cunha serviu de matriz do pensamento de escritores e intelectuais que se propuseram a descrever, representar e interpretar a favela. Assim, segundo ela, as características atribuídas por Euclides da Cunha ao sertão baiano e ao povoado de Canudos foram, também, reconhecidas como atributos da favela, como o crescimento urbano rápido e desordenado, a topografia, a ausência de propriedade privada, a ausência de um domínio do Estado, a ordem política marcada pelo domínio do chefe, o condicionamento do ambiente na personalidade de seu residente, a imoralidade, o perigo para a ordem social e a liberdade excessiva.

A associação entre o sertão e a favela permitia, portanto, reinterpretar a cidade do Rio de Janeiro, conferir sentido às aglomerações de casebres nos morros, estabelecendo as relações existentes entre sujeitos, objetos e ações. A partir da matriz fornecida por Euclides da Cunha, foi possível atribuir aos moradores das favelas as características que ele observara nos habitantes de Canudos.

Mas quem são os habitantes de Canudos para Euclides da Cunha? Na entrada da exibição, vemos uma citação do autor, em que ele diz que o sertanejo é, antes de tudo, um forte. Usa-se muito essa citação para falar do sertanejo e, fora de contexto, ela até 
parece ser um elogio. Contudo, para o autor, o sertanejo, como os demais tipos de "mestiço", pertence a "raças inferiores", possui uma "deplorável situação mental" (CUNHA, 1982 [1902], p. 07), um "espírito predisposto para a rebeldia franca contra a ordem natural" 2 e "temperamento impulsivo": é "valente por instinto" 3.

Só para vocês terem uma ideia do pensamento racista da época, Nina Rodrigues (1894), um dos precursores da Antropologia no Brasil e citado por Euclides da Cunha em "Os sertões", dizia que não se poderia exigir que as "raças distintas" respondessem por seus atos perante a lei com igual plenitude de responsabilidade penal, pois não teriam, ainda, adquirido o desenvolvimento físico e a soma de faculdades psíquicas suficientes para reconhecer, num caso dado, o valor de seu ato (discernimento) e para decidir livremente se comete ou não o crime (livre arbítrio).

Rodrigues nega, assim, à grande parte da população nacional, a consciência. Nega-lhes a palavra, a possibilidade de manifestar o útil e o nocivo, o justo e o injusto. A eles se atribui apenas o ruído. Nos termos da teoria política clássica, poderíamos dizer que, para Rodrigues (assim como para Euclides da Cunha), os indivíduos de "raças inferiores" possuem apenas phoné, e não logos. Ou para sermos mais justos com o pensamento de Rodrigues: eles compreendem um logos, e talvez até o possuam, mas somente como expressão pueril, própria de seres que pertencem "a uma outra fase do desenvolvimento intelectual e moral” (RODRIGUES, 1894, p. 156). Eles podem até se conter pelo temor do castigo e receio de violências, mas absolutamente "não terão consciência de que seus atos possam implicar a violação de um dever ou o exercício de um direito" (RODRIGUES, 1894, p. 148). Desse modo, eles ocupam um "não-lugar" discursivo, têm negado seu estatuto de inteligibilidade discursiva, seu estatuto de pessoa, pois são apontados como sujeitos perigosos e caracterizados como abjetos, destrutivos e irracionais.

Como, então, estabelecer uma comunidade política num contex to no qual uma grande parcela desta só participa da linguagem sob a forma de compreensão e não de posse? Entre a linguagem dos brancos e os ruídos das "raças inferiores", não há situação de troca linguística que possa ser constituída, não há regras ou códigos para a discussão.

Além disso, para agravar o problema, aos sertanejos (e, mais tarde, aos favelados) também é negada a coetaneidade, visto que não habitam um mesmo tempo em relação aos brancos, não pertencem ao presente, à modernidade, mas sim, ao passado

\footnotetext{
2 Ibid., p. 117

3 Ibid., p. 205 
primitivo. Henrique Dodsworth, em artigo no Correio da Manhã, em 1956, lembra que Euclides da Cunha referia-se às favelas do Rio como "cidades que já nascem velhas" (CORREIO DA MANHÃ, 28/03/1956). Em “Os Sertões”, o autor já resumia o pensamento corrente ao afirmar que entre o "nosso mundo" (leia-se o mundo do litoral “civilizado" e branco) e o daqueles "rudes patrícios" (os sertanejos) a distância é maior do que em relação aos europeus. Segundo ele, os povos do sertão seriam "mais estrangeiros nesta terra do que os imigrantes da Europa. Porque não no-los separa um mar, separamno-los três séculos" (CUNHA, 1982 [1902], p. 153).

Só que aconteceu algo inesperado. Aconteceu que esses “incapazes” sertanejos, esses "retardatários" da civilização, impuseram uma série de derrotas ao exército brasileiro, que teve de enviar não uma, não duas, mas quatro expedições para vencer a batalha. E isso deixou a nossa elite branca perplexa. Afinal, como podiam esses seres considerados inferiores, mal armados e treinados, vencer um exército comandado por dirigentes brancos, experientes e bem preparados?

Na terceira expedição, o exército enviou ninguém menos que Antônio Moreira César, considerado pelos militares um herói do exército brasileiro, famoso debelador de revoltas e popularmente conhecido como "corta-cabeças" por ter mandado executar mais de cem pessoas a sangue frio na repressão à Revolução Federalista em Santa Catarina. Mas Moreira César também cairia em Canudos, com um tiro na barriga.

Nos jornais do Rio, estampavam-se as explicações para mais um insucesso, e não faltaram aqueles que o viram como a mais clara evidência de que, à sombra do fanatismo religioso, marchava o movimento monarquista rumo à restauração. Os jornais monarquistas no Rio chegaram, inclusive, a ser atacados pela multidão na Rua do Ouvidor, aos gritos de "Viva a República!” (CUNHA, 1982 [1902], p. 261).

Euclides da Cunha, porém, condenava a reação. Segundo ele, "atribuir a uma conjuração política qualquer a crise sertaneja exprimia palmar insciência das condições naturais da nossa raça” " Afinal de contas, o sertanejo é "tão inapto para apreender a forma republicana como a monárquico-constitucional", visto que se encontrava "na fase evolutiva em que só é conceptível o império de um chefe sacerdotal ou guerreiro" ${ }^{5}$.

Contudo, Euclides afirmava que apesar de pertencer a raças inferiores, apesar de ser um sujeito incapaz e ignorante, o sertanejo é fisicamente forte e altamente adaptado ao primitivo ambiente em que vive, diferentemente dos "mestiços indefinidos e

\footnotetext{
${ }^{4}$ Ibid., p. 262

${ }^{5}$ Ibid., p. 152
} 
pusilânimes" ${ }^{6}$ que formavam boa parte dos soldados da República. O isolamento, segundo ele, permitia que os sertanejos formassem uma subcategoria étnica, pois permaneceram "protegidos" da civilização, livres da "adaptação penosíssima a um estágio social superior" ${ }^{7}$. Assim, puderam tomar do selvagem a intimidade com o meio físico e livrar-se das "aberrações e vícios dos meios adiantados" 8.

O autor clama para que não subestimem o sertanejo, dado que a aparência de cansado, segundo ele, ilude. A apatia em que se encontra durante a maior parte do tempo, transforma-se de uma hora para outra, como num impulso violento. Quando está a cavalo, diz Cunha, mais parece um "centauro bronco". E nada consegue contê-lo. Para ele, o sertanejo é instável e perigoso, "caracterizado sempre pela intercadência impressionadora entre extremos impulsos e apatias longas" 9.

É verdade que Euclides via algo de autêntico nos sertões, algo genuinamente brasileiro, e que ele se indignou com as "covardias repugnantes" e as torturas a que impunham os soldados aos vencidos de Canudos. Para ele, a solução não era a utilização da força bruta, pois, como ele mesmo afirma, "a raça forte não destrói a fraca pelas armas, esmaga-a pela civilização" ${ }^{10}$. Euclides insistia que era imperioso que as elites intelectuais e políticas deixassem de lado os modelos europeus e olhassem o país dos sertões. Porém, ao mesmo tempo, alertava para o fato de que movimentos semelhantes ao de Canudos poderiam ocorrer se não fossem adotadas políticas que rompessem o isolamento dessas populações. Deixá-los isolados, livres, sem controle e sem vigilância era colocar em risco a própria República.

Só que, agora, os desordeiros e facínoras de Canudos, como eram chamados, tinham encontrado seu lugar no coração da capital. E eles não são desordeiros e facínoras porque pertenciam às tropas de Antônio Conselheiro ou porque eram soldados que tinham participado de um genocídio naquela cidade. Não. Eles são o que são para a nossa elite porque pertencem às mesmas raças. Não importa de que lado lutaram ou mesmo se lutaram: são degenerados, retrógrados, pessoas brutas, primitivas e perigosas.

Nesse sentido, chamar o morro carioca de Morro da Favella é, em primeiro lugar, atribuir ao morro, àquela comunidade, um elemento de perigo, um elemento

\footnotetext{
${ }^{6}$ Ibid., p. 431

7 Ibid., p. 89

8 Ibid., p. 89

${ }^{9}$ Ibid., p. 92

10 lbid., p. 89
} 
ameaçador. O jornal A Noite, em 04 de junho de 1902, conta a sua versão de como o morro da Providência passou a ser chamado de Favella:

Tão frequentes se tornaram os crimes e as cenas de sangue entre os residentes na parte do morro da Providência próximo à Cruz do Novo-Século, que ficou aquele local mais conhecido por morro da Favella, recordando o lugar onde em Canudos maiores vítimas fez aquela campanha.

Já o jornal Correio da Manhã, em 1909, descreve o malsinado morro carioca como "o lugar onde reside a maior parte dos valentes da nossa terra (...) esconderijo de gente disposta a matar, por qualquer motivo, ou, até mesmo, sem motivo algum” (CORREIO DA MANHÃ, 05/07/1909). Segundo a Revista da Semana, de 15 de janeiro de 1916, as "diversas Favellas" do Rio constituem "aldeamentos africanos", "bairros vergonhosos, cuja vista nos transporta o pensamento para o âmago dos sertões ínvios, de onde vêm as tribos dos silvícolas”. Segundo a matéria, a cidade não poderia reivindicar os foros de uma grande capital civilizada enquanto tiver que conviver com esta "paisagem sertaneja”.

Desde que a palavra "favela" emergiu como substantivo comum, ela foi logo identificada como um espaço racialmente definido. Determinado não pelos seus atos, mas pelo seu modo de ser, pela sua própria psicofisiologia, o morador da favela, condenado pela raça, é sempre um excessivo, um instável, um irregular, um descontínuo, um subversivo. Em artigo do jornal A Noite, em 15 de agosto de 1911, o autor denuncia o perigo da disseminação das favelas e de sua população, "cuja característica é a rebeldia à ordem e ao progresso".

E é claro que a associação entre Canudos e as favelas foi uma associação que teve efeitos concretos na forma como o Estado iria orientar as suas políticas e as suas práticas em relação a essas comunidades. Seja como for, o ponto que gostaria de frisar é que essa associação foi a pedra de toque da construção de um discurso exterior sobre a origem dessas comunidades e sobre os atributos de seus moradores. Um discurso estigmatizante, racista e violento.

\section{Maurício Hora e a reinterpretação do mito de origem da favela}

Tendo em vista tudo isso que disse até aqui, talvez vocês me entendam melhor quando eu confessar que, quando entrei nesta exposição e me deparei com o painel que diz que Maurício Hora tinha ido a Canudos para compreender as origens da favela, para 
buscar a identidade social da favela por meio das linearidades históricas entre Canudos e o Morro da Providência, eu pensei: Ora, fazer isso é referendar uma história inventada para estigmatizar a favela. Uma história que silencia as origens de resistência representadas pelos quilombos e que condena a favela a ser uma eterna inimiga da cidade, uma ameaça à sua existência.

No entanto, durante a exposição, comecei a notar que aquilo que via não reproduzia uma história já contada, mas reinterpretava e transformava o mito de origem da favela. O olhar de Maurício não é um olhar de historiador, olhar de quem busca revelar ou analisar acontecimentos do passado. É um olhar artístico que reivindica a história de Canudos como parte de sua própria história, com a autoridade de quem nasceu e cresceu na Favella. Um olhar de quem, buscando conhecer a si mesmo, reconstrói o passado e ressignifica o presente através da arte, revelando a beleza, a criatividade e a enorme diversidade de pessoas e paisagens que, por tanto tempo, foram representadas como primitivas, degeneradas e perigosas. Percebi, assim, que aquele painel inicial estava enganado, pois Maurício não buscava a identidade social da favela nas linearidades históricas entre Canudos e a Providência: ele as criava. Tecia, cuidadosamente, por meio de imagens e entrevistas, novos fios a ligar o sertão à favela.

Dividida em dois lados opostos, um para Canudos e outro para a Providência, mas sem delimitar uma fronteira clara, a exposição incita o visitante a realizar um exercício de comparação. No lado de Canudos, a terra e a água ganham protagonismo, quase sempre acompanhadas de um horizonte tomado pelo céu azul. Enquanto as fotos alternam imagens da seca e imagens de barcos boiando em um lago ou crianças brincando na água; as casas de sopapo ou pau-a-pique parecem ter se erguido espontaneamente do chão que as sustenta, quase como se o solo e a casa formassem um só corpo (fig. 1).

$\mathrm{Na}$ Providência, por seu turno, o horizonte é distante e marcado pelo concreto dos prédios altos ou das luzes que brilham no centro da cidade. Lá, predominam as casas de alvenaria, mas Hora sabe bem onde encontrar construções de esteios e de pau-a-pique. Contudo, deste lado da exposição, a ruptura e o contraste tomam o lugar da continuidade entre a habitação e a paisagem notada em nova Canudos. Em uma das fotografias (fig. 2), a cidade do Rio é emoldurada pela paisagem da Providência, explicitando de forma clara a perspectiva do fotógrafo. As raízes expostas de uma árvore, que se agarra teimosamente ao chão, formam a metáfora perfeita da história de resistência de ambas as comunidades. A luz, por sua vez, projeta sobre a moldura uma cor avermelhada que nos 
remete novamente às imagens da nova Canudos, realçando o vermelho dos tijolos e fazendo com que a terra e até mesmo o muro de cimento se assemelhem à tonalidade do barro sertanejo. Da Favella - agora unificada numa síntese entre o morro carioca e o baiano - mira-se a cidade que a fez inimiga e a modernidade que foi seu algoz.

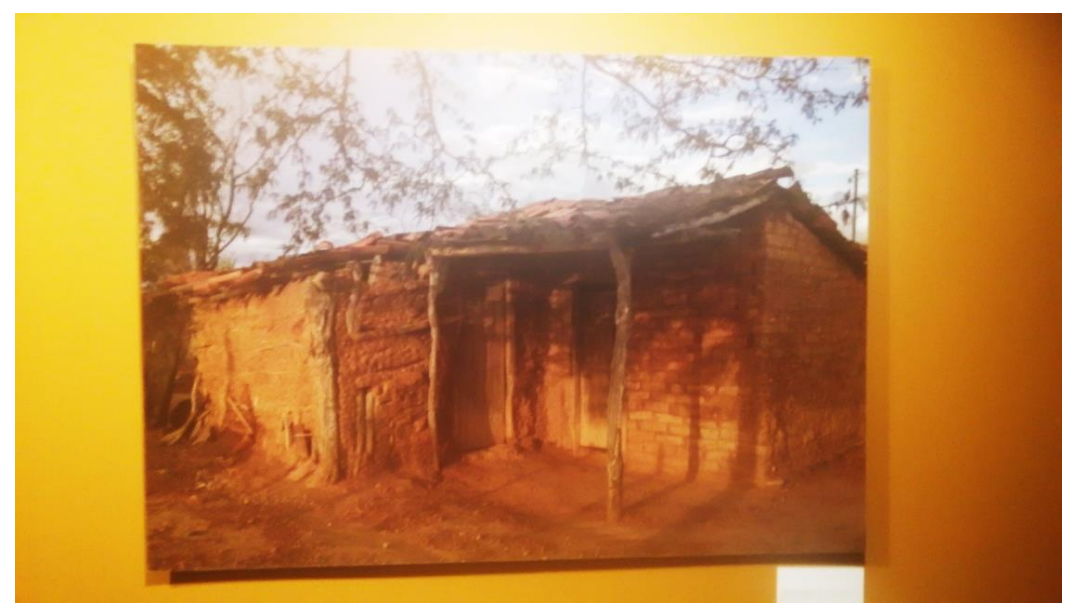

Figura 1. Figura 1: A foto de Maurício Hora mostra uma casa de barro no município de Canudos. Desde o início do século XX, especialmente devido à ação dos sanitaristas, a casa de taipa (ou mocambo) foi concebida como inimigo número 1 da Higiene, e considerada responsável pelas endemias que acometiam os moradores da região (ALMEIDA, 2016; 2017). Fonte: Própria.

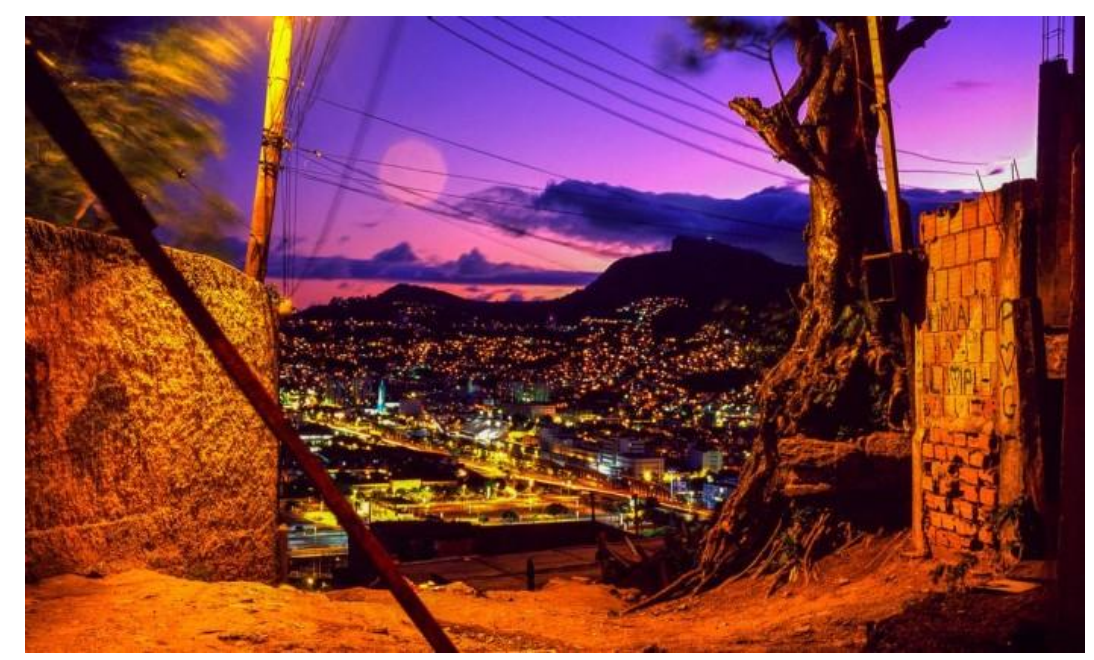

Figura 2. Tirada do alto do Morro da Providência, a foto parece unificar os dois mundos (de Canudos e da Providência), ao mesmo tempo em que os diferencia da cidade moderna, que emerge distante no horizonte. Fonte: https://oglobo.globo.com/rio/morro-da-providencia-ganha-exposicao-que-conta-120-anos-dehistoria-em-fotos-21368652. Fotografia de Maurício Hora.

As fotos da nova Canudos me reportam imediatamente à figura do fotógrafo Flávio de Barros, imortalizado por suas imagens da guerra de Canudos. Contratado para documentar o conflito, sua obra em muito se difere dos objetivos artísticos de Maurício Hora. Como observa Berthold Zilly (1999), Barros documenta o olhar do vencedor, 
enaltece a vitória da civilização sobre o atraso, destacando a aspereza do solo e as poses robustas e ostensivas dos oficiais. Já as fotos dos sertanejos vencidos na batalha, como a "Rendição dos conselheiristas em 2 de outubro" ou "Jagunço preso", parecem coadunarse com a descrição caricata de Euclides, criando uma espécie de "máscara", fazendo da face "o produto de uma sociedade e de sua história” (BARTHES, 1984, p. 58)

Nas imagens de Maurício, todavia, a "civilização", tal como compreendida pelos arautos do progresso, sequer aparece. É como se todo o alvoroço causado pela guerra, todas as juras de amor à República e as promessas de um mundo moderno tivessem sido apagadas pelo tempo.

Lembrada somente ante as ruínas, a "civilização" redentora se esvazia, é evocada apenas como cicatriz decadente da destruição. Os laivos de heroísmo das fotos estáticas dos soldados em grupo (das imagens de Barros) são substituídos pela mundanidade dos deslocamentos para o trabalho e da correria do desenfadar infantil.

De algum modo, Maurício parece intuir que a chama a alimentar a capacidade incessante de ressurgir, de renascer ou de fincar raízes, mesmo quando o mundo conjura o desterro, talvez não se encontre somente na revolta que marca as histórias de Canudos e da Providência, mas sim, noutro lugar, num lugar mais próximo, mais familiar: no próprio cotidiano dos moradores.

Em ambos os lados da exposição, observamos seus residentes cumprindo tarefas costumeiras, habituais. As ruínas da Velha Canudos contrapõem-se à vida inscrita tanto no sorriso travesso das crianças quanto nas rugas expressivas daqueles que trazem consigo, na própria pele, as marcas e a memória de tempos passados. É como se a vida, negando-se a extinguir-se pelas baionetas do Estado ou pelas águas do Progresso, fora transposta para a cidade refundada. E é precisamente essa vida que encontramos, também, na cidade moderna, no alto desse morro que tantas vezes quiseram demolir e extirpar da paisagem carioca.

O olhar de Maurício é, portanto, um olhar antropofágico. Porque devora a narrativa racista de Euclides da Cunha, devora o "mito de origem da favela" e tudo que foi associado a ele, e produz uma outra história, uma história com gente de verdade e não tipos antropológicos, dando a oportunidade ao visitante de entrar na casa de taipa, no mocambo, no barraco e ouvir, nos vídeos das entrevistas, uma outra narrativa (Fig. 3 e 4). Uma narrativa que não pertence a nenhum doutor da Academia, nenhum literato puro-sangue, mas uma narrativa que é viva e plural. 


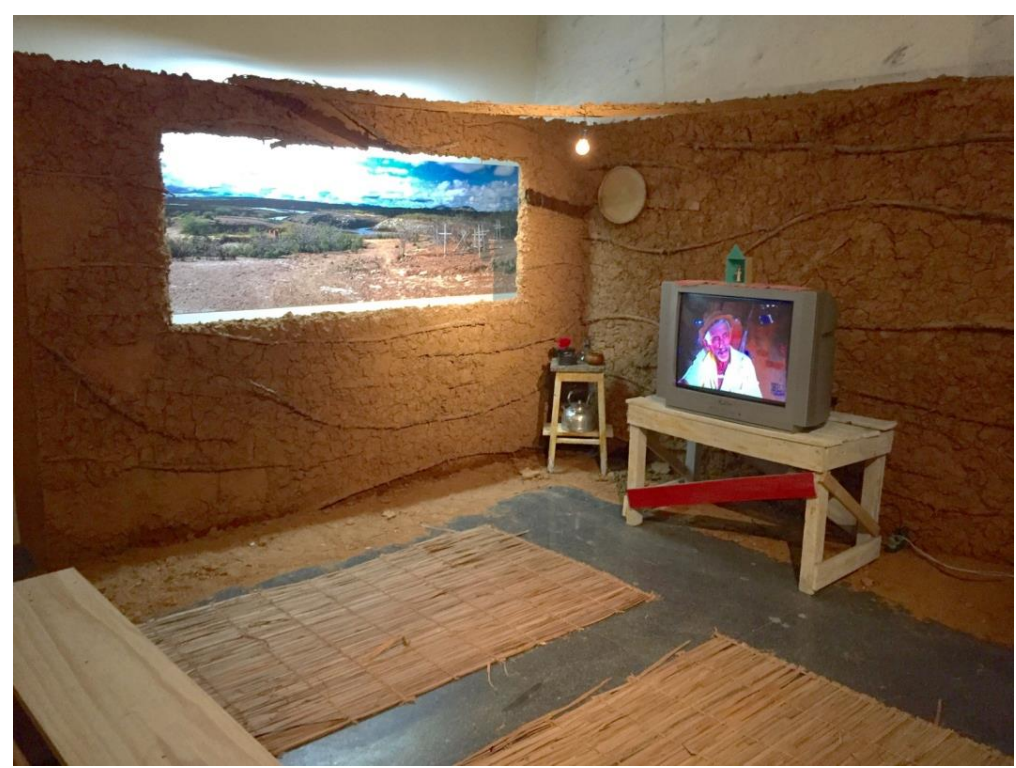

Figura 3. Maurício Hora constrói um espaço que se assemelha à casa de taipa. Nele, uma TV mostra vídeos com as entrevistas de moradores de Canudos. Fonte: https://rioonwatch.org.br/?p=26172\#prettyPhoto/2/

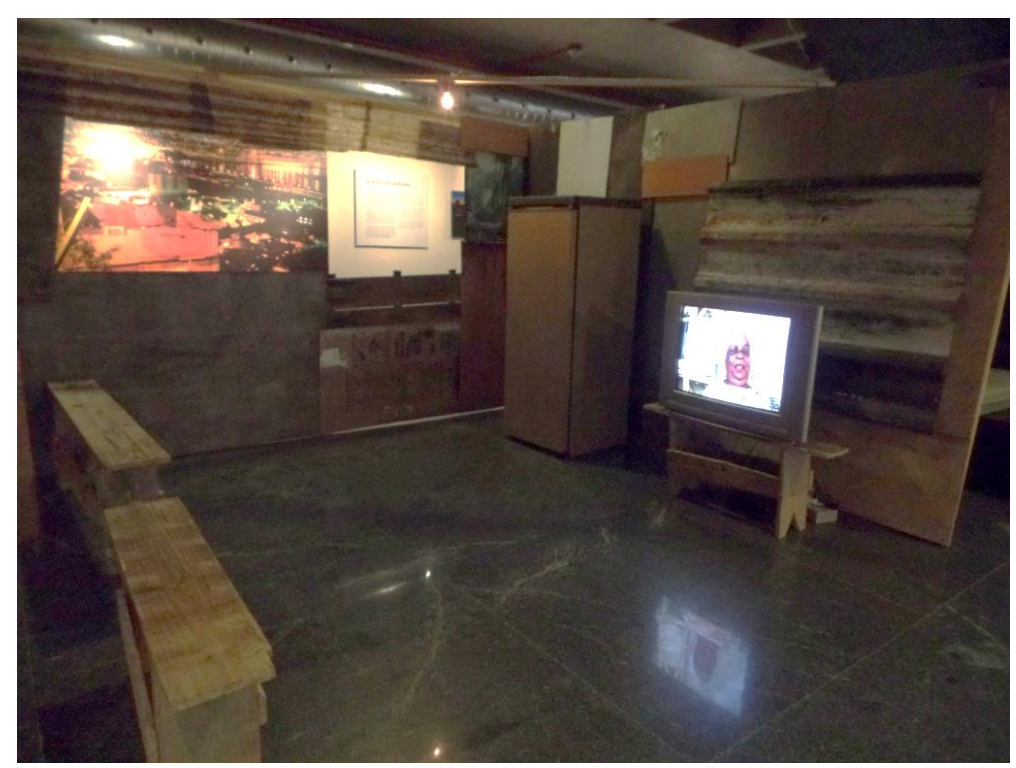

Figura 4. Assim como na casa de taipa da figura anterior, aqui podemos ver as falas dos moradores da Providência, contando suas histórias e da comunidade onde vivem. Fonte: Própria.

É da boca dos moradores de Canudos que o visitante aprende sobre a história do conflito, enquanto as falas dos moradores da Providência estabelecem os vínculos com o sertão baiano. Assim, as épicas narrativas do sertão transformam-se em conversas informais sob uma luz fraca. Nelas, os interlocutores riem, se emocionam e choram ao contar histórias que, mesmo quando passadas antes de nascerem, nem por isso são menos pessoais, familiares e íntimas. De certa forma, a exposição restitui o estatuto de pessoa dos habitantes de Canudos, restitui a possibilidade da fala e, mesmo que por um instante, 
devolve a palavra que lhes foi roubada por Euclides da Cunha e afogada por Getúlio, quando mandou inundar a cidade para construir um açude.

Assistindo às entrevistas, paro para pensar sobre a curiosa importância que as palavras assumem nesta exposição fotográfica. Afinal, não foi precisamente a força de uma palavra, a "favela", que, movida pelas contingências da história, foi capaz de aproximar dois mundos tão distintos, tornando-os para sempre umbilicalmente ligados um ao outro?

Há, contudo, algo mais, algo que une a exibição à biografia do artista que encontrou, nas fotografias, um meio de contar a sua própria história. O recurso dos vídeos complementa as imagens, fazendo com que os sertanejos e os moradores da Providência deixem de ser apenas um objeto da exposição. Com isso, Maurício acentua que o que está em jogo é precisamente o direito político de ser sujeito.

Caminhando pela galeria, já tendo percorrido os dois lados, me deparo com a escultura de uma ruína da Velha Canudos (fig. 5), que somente se deixou capturar pelas lentes de Maurício devido à grave seca que castigou o sertão baiano naquele ano e reduziu o nível de água do açude. Posicionada quase no centro da sala, era como se representasse um elo a entrelaçar o passado ao presente, Canudos ao Morro da Providência, como uma encruzilhada de diferentes tempos e espaços.

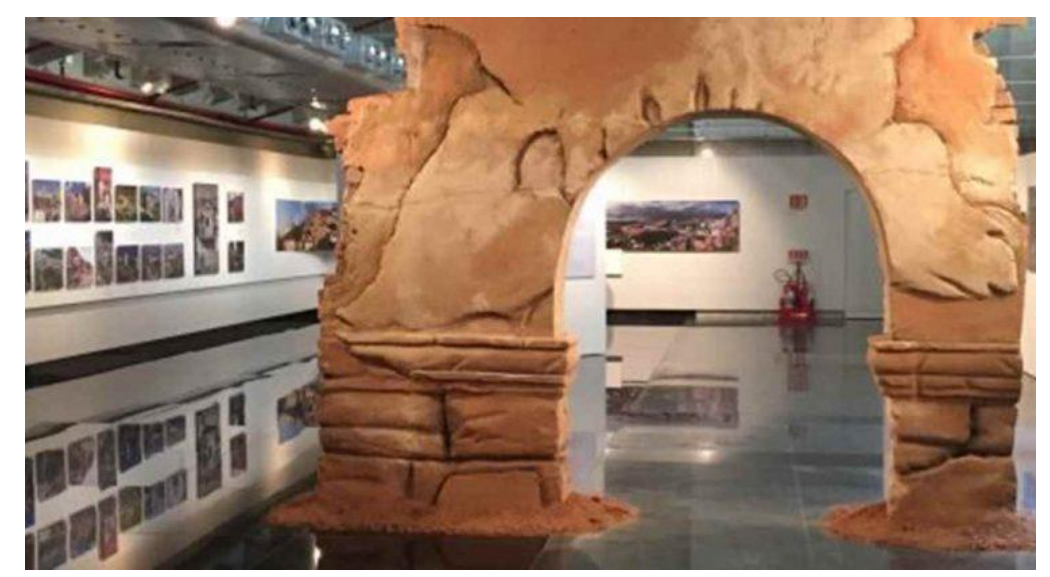

Figura 5. Escultura que replica as ruínas presentes em Canudos, hoje submersa pelas águas do açude. Fonte: https://racismoambiental.net.br/2017/06/15/de-canudos-a-providencia-mais-de-120-anos-dememoria/

E não pude evitar pensar que, assim como em Canudos, as ruínas do passado das favelas - esses vestígios da violência covarde e destruidora que sempre se abateu sobre elas - ainda hão de ressurgir, mais cedo ou mais tarde, para lembrar-nos dos nossos erros e omissões e para, quem sabe, finalmente, acertar os soldos devidos e nunca pagos. 
Pois não há água nesse mundo capaz de afogar essa história que não se encontra nos livros, essa história que se carrega no corpo, na dor do luto dos que hoje choram a morte de Paulo Henrique, de treze anos de idade (morto no Complexo do Alemão); de Fernanda Adriana, de sete, baleada enquanto brincava no terraço de sua casa na favela Parque União; de Maria Eduarda, de treze, baleada dentro da escola em Acari; de Roberto, Wilton, Cleiton, Carlos Eduardo e Wesley, executados por policiais em Costa Barros, quando voltavam de um passeio ao Parque Madureira; e de tantos outros.

Parado ao lado da escultura, imerso em meus pensamentos, ergo os olhos mais uma vez para contemplar a exposição. E creio ter, nesse momento, entendido a importância de afirmar a associação entre o episódio de Canudos e as favelas do Rio de Janeiro. Como negar que a história dessa gente corajosa, que lutou contra e venceu três vezes um Estado racista e genocida, também faz parte da história das favelas? Afinal de contas, desde então, a favela resiste às mesmas forças genocidas, racistas e covardes do Estado brasileiro. Desde então, tentam erradicá-la, extinguir a cultura, as crenças e a arte das favelas, criando estigmas, projetando inferioridade. A exposição de Maurício, com sua sensibilidade ímpar, lembrou-me, por fim, que o passado é vivo e presente, sobrevive ao amanhã, se abre para o futuro e para a criação.

Ao vincular a favela a Canudos, Maurício se lança sobre aquele povoado com o olhar de quem busca encontrar-se no "outro". Por isso, ele não visita Canudos, ele a habita. Nativo exilado, retorna estrangeiro para finalmente descobrir que por trás das máscaras dos semblantes sertanejos das fotos de Barros, encontra-se um espelho.

\section{AGRADECIMENTOS}

Agradeço a Julia Cossermelli de Andrade pelo convite para participar do debate sobre a exposição de Maurício Hora, e a Marianna Fernandes Moreira pela leitura crítica do artigo.

\section{REFERÊNCIAS BIBLIOGRÁFICAS}

ABREU, Maurício Almeida (1994). Reconstruindo uma História Esquecida: origem e expansão inicial das favelas do Rio. In: Espaço \&̊ Debates. São Paulo, v.14, n. 37, pp. 34-46.

AGACHE, Alfred. (1930). Cidade do Rio de Janeiro: extensão - remodelação - embelezamento. Rio de Janeiro, Prefeitura do Distrito Federal.

ALMEIDA, Rafael Gonçalves de. (2016). Favelas do Rio de Janeiro: a geografia histórica da invenção do espaço. Tese (Doutorado em Geografia). Universidade Federal do Rio de Janeiro, Rio de Janeiro.

(2017). A emergência da favela como objeto da prática médica: Do neohipocrastismo à teoria dos germes. Terra Brasilis (Nova Série) nº 8 , pp.1-19. 
BACKHEUSER, Everardo (1906). Habitações populares. Relatório apresentado ao Exm. Sr. Dr. J.J. Seabra, ministro da Justiça e Negócios Interiores. Rio de Janeiro, Imprensa Nacional.

BARTHES, Roland (1984). A câmara clara: Nota sobre a fotografia. Tradução: Julio Castanon Guimarães. 9a impressão. Rio de janeiro: Nova Fronteira.

CAMPOS, Andrelino de Oliveira (2004). Do Quilombo à Favela: a criação do "espaço criminalizado" no Rio de Janeiro. Rio de Janeiro: Bertrand Brasil.

CUNHA, Euclides da (1982 [1902]). Os Sertões: Campanha de Canudos. São Paulo: Abril Cultural.

KARASCH, Mary (2000). A vida dos escravos no Rio de Janeiro: 1808 -1850. São Paulo: Companhia das Letras.

LIMA, Nísia Trindade (2013). Um sertão chamado Brasil. São Paulo: Hucitec Editora. $2^{a}$ Ed. Col. Pensamento Político-social.

MOURA, Vitor Tavares de (1943): Favelas do Distrito Federal, In: Aspectos do Distrito Federal, Rio de Janeiro, Academia Carioca de Letras, Gráfica Sauer.

RODRIGUES, Nina (1894). As raças humanas. Salvador: Progresso.

SANTOS, Wanderley Guilherme (1978) Ordem Burguesa e Liberalismo Político. São Paulo: Duas Cidades.

VALLADARES, Licia do Prado (2000): A gênese da favela carioca; a produção anterior às ciências sociais. Revista Brasileira de Ciências Sociais. Vol. 15, n. 44. pp. 5-34.

FGV.

(2005): A invenção da favela: do mito de origem a favela.com. Rio de Janeiro:

ZILLY, Berthold (1999). Flávio de Barros, o ilustre cronista anônimo da guerra de Canudos. Estudos Avançados, 13 (35), p. 105-113.

\section{MATERIAL DE IMPRENSA}

A Noite

Correio da Manhã

Revista da Semana 